\title{
On the Objectivity of Facts, Beliefs, and Values
}

\author{
Wolfgang Spohn \\ Department of Philosophy \\ University of Konstanz \\ D - 78457 Konstanz \\ Germany
}

Objectivity is a well-belabored topic. The point of this paper can only be a modest one: to introduce some distinctions for conceptual clarity, to sketch the routes to objectivity which appear most plausible on the background of the current discussion, and to point to some errors which make present confusions larger than necessary. These points seem well worth pursuing also in the context of the present conference volume.

The main distinction will be between a notion of objectivity accruing to facts and thus to objects and properties and building on ontological independence and a quite different notion of objectivity accruing to beliefs and idealizing intersubjective agreement. We shall see that the latter notion is in principle applicable to values as well. The difference is only that there are stronger specific reasons for hoping for objectivity in the case of beliefs and stronger specific reasons for restricting claims to objectivity in the case of values.

This is, briefly, the agenda of this note. Let me start with the objectivity of facts and then proceed to that of beliefs and values.

\section{On the Objectivity of Facts}

When Hume was struggling with and despairing of the objectivity of objects, his concern was about the continuity and the independence of external objects. ${ }^{1}$ External to what? The answer is not really important; I shall return to the point.

\footnotetext{
1 See the section "Of Scepticism with regard to the Senses" in Hume (1739/40, I. iv. 2), and, e.g., Bennett (1971, ch. XIII).
} 
Continuity is not so important, either; there are also discontinuous, but perfectly objective objects. ${ }^{2}$ The crucial feature of objects that makes for their objectivity is their independence. How is independence here to be understood $?^{3}$ It is ontological independence from us; this has always been intended as one basic sense of objectivity.

What is ontological independence? An object $x$ ontologically depends on an object $y$ if $x$ cannot exist without $y$, if it is metaphysically impossible that $x$ exists, but not $y$. For instance, each human being ontologically depends on its mother, or has its mother essentially. Conversely, $x$ is ontologically independent from $y$, if $x$ might exist even if $y$ does not exist.

And who is us in this context? There is a little vagueness here. If it is to be the whole of mankind, then Henry Ford or, respectively, my ancestors and I must be exempt from it in order for my Ford or me myself to acquire objective existence. So, "us" rather refers to human minds. This secures my objective existence; I may lose my mind and still exist. But the vagueness persists. My perceptions ontologically depend on my mind, but not on other minds or objects ${ }^{4}$; still, I don't see why my perceptions should be denied objective existence.

The same vagueness affects, by the way, the notion of an external object. "External" means here "spatially external to us", and so we might again wonder who is us. But it is not so important to resolve the vagueness. The objectivity issue is not about potential borderline cases like my perceptions, me, or my Ford, but rather about objects in general, no matter how we draw the borderline.

In one way or the other, it was always scepticism that motivated the general denial of the objective existence of objects. If we follow, for instance, Berkeley's idealistic doctrine esse est percipi or conceive of external objects in a phenomenalistic way as mere constructions from sense data, then objects ontologically depend on perceptions or perceiving subjects and are not objective. ${ }^{5}$ Or if we follow more sophisticated Kantian idealism or its modern heritage, the many variants of constructivism, then the external world and its objects ontologically depends on

\footnotetext{
2 The journal Erkenntnis, for instance, which existed from 1930 to 1939 and then from 1975 onwards, definitely in an objective manner, as I am privileged to say.

3 Independence is one of the worst notions in philosophy, equally multiply ambiguous as, say, necessity.

4 At least, this is what one would normally say. But there may be sophisticated individuations, e.g., externalistic accounts of perceptions and perceptual contents according to which their ontological dependence spreads further.

5 If the perceiving subject is God and if God is objective, the case is different, of course.
} 
our concepts; the world and the objects could not be what they are if our concepts would not be what they are, if we would conceive them with different concepts. Again, they are not objective. ${ }^{6}$

I think, and many of thought so before, that this comes to a straightforward refutation of all these kinds of phenomenalism or constructivism. No motive can be good enough for going ontologically crazy. We may indeed be tempted to endorse such doctrines, but then the only reasonable response is to stop the temptation and to inquire what has led ourselves so far astray.

This might have been the sceptical question: how do we know that objects are objective? - temptingly suggesting that we can't really know. Well, how do we know anything? And in particular how do we know about counterfactuals (such as objectivity claims)? These are good questions, and even if we have some way of answering the first general one, the second about counterfactuals may remain mind-boggling. There is every reason for the vigorous interest in counterfactuals in the last 35 or 55 years. Still, with these questions we are leaving ontology and entering epistemology, and there is no ontological conclusion to be drawn from epistemological issues and in particular no way to resort from epistemological despair to ontological insanity.

Another tempting thought is that it is we who cut up the world into parts and pieces, who constitute objects, that we do so with our conceptual power, and that we might do it differently, if we faced the world with different concepts. This sounds true, and it seems to directly lead to some kind of constructivism. I think it is true, but it has no such consequences. It is simply false in general to say that an object would not exist unless constituted (by us or whomever) or that there would be different objects if we constituted them differently. This may apply to some special objects, for instance our concepts themselves. But in general there is no way for the constructivist to get beyond such counterfactual trivialities as: if nobody conceived or named objects, nobody would conceive or name them, or if we would constitute different objects, we would think and talk about different objects, or without constitution no constitution. Any stronger constructivist claim rests on a misunderstanding of constitution. The objects do not come to exist by getting constituted. The whole point of constituting objects is normally to fix their constitutive or essential properties in such a way that the constituting or fixing

\footnotetext{
6 See also the devastating and, I think, justified criticism of the various kinds of constructivism in Devitt (1984, chs. 8-14).
} 
does not belong to them; hence, they would exist just as well unconstituted. The constitution of objects and the ruling of how to correctly talk about them counterfactually is one and the same matter, and we do it usually so as to acknowledge their ontological independence from us, i.e., their objectivity.

The same holds, mutatis mutandis, for properties. The talk of existence and ontological independence refers only to objects, not to properties. Still, we may say that a property is objective insofar its extension, whether or not it applies to a certain object, is counterfactually independent of us or our minds, of what we or our minds do.

Colors provide a striking example. The relation of $x$ looking red to $y$ is not objective in this sense. That a certain tomato looks red to me counterfactually depends on my existence, on my being awake, on my not wearing strongly colored glasses, etc. (though it does not counterfactually depend on the existence of others - remind the vagueness of "us"). The same holds for the property of being appeared to redly, as Chisholm once phrased it. The contrary, however, holds for the property of being red. This tomato is red, and it would still be red, even if it is unperceived or if there is nobody at all or only organisms with a different color vision to perceive it. These counterfactual claims seem obviously true to me. They are also compatible with the fact that which property is actually denoted by "being red" depends on our neurophysiological and mental make-up (in ways we understand still quite incompletely). But this dependence cannot be expressed by counterfactuals about what is or would be red. The property of being red itself is no longer dependent in this way. ${ }^{7}$ Hence, being red is an objective property, and so are other properties all the more.

Objects and properties make up states of affairs, and, if they obtain, facts. This is why the title of this section summarizes the observation made so far.

I shall, however, not deepen now these observations and pursue this notion of objectivity any further. One obvious reason is that there would be no end in doing so. A more specific reason is that I would like to discuss values in the end, and that this notion of objectivity does not seem to be helpful when it comes to values. In any case, I don't see how values could be objective in this sense. Values seem to ontologically depend on valuers. Things can be red in a possible world without perceivers, but things can't be valuable in a possible world without valuers. One

\footnotetext{
7 This may sound like objectivism about color according to Jackson, Pargetter (1987). But in fact, it is my own, I think, more defensible version explained in detail in Spohn (1997).
} 
can argue about who is a valuer; presumably not only humans. But stars and stones are none, I take it, and hence nothing has any worth in a world in which there are only stars and stones. They may do this or do that or all disappear in a black hole; nobody cares. ${ }^{8}$ Hence, if this is right, we have to look for other notions of objectivity in order to possibly make sense of objective values.

Still, the present ontological notion of objectivity is perhaps the most basic one, deeply worrying, as we have seen, philosophy for centuries. And it is well worth being reminded here, because the deeper philosophy of science gets involved into the epistemological workings, the more careless it gets about the ontological dimension, and the more easily it slips into talking nonsense. Let me add, therefore, just one general remark:

We are always prone to mix ontological and epistemological issues; and we often hardly notice it. The best measure against this danger is to move within a framework within which the two dimensions are clearly separated from the outset. Such a framework exists and is even formally codified. It is called two-dimensional semantics nowadays, but this title hides its origins. It has also been called, circumstantially, the epistemological reinterpretation of the character theory, where "character theory" refers to Kaplan (1977) and "epistemological interpretation" to Stalnaker (1978) and both refer further back to Kripke's and Putnam's ground-breaking attempts to disentangle metaphysical and epistemic necessity. As the name says, these two dimensions and their relation are formally represented in two-dimensional semantics. ${ }^{9}$ Of course, the details of interpretation present difficult issues (and sometimes perhaps old issues in a new disguise). ${ }^{10}$ Still, the framework is the best device we have for sorting out ontological-epistemological confusions.

For instance, to mention a particularly relevant example, it makes clear that the notion of intension, which was once to explicate the notion of meaning in the sense of truth condition, is systematically ambiguous. There are diagonals and intensions (Stalnaker), primary and secondary intensions (Chalmers), or A- and Cintensions (Jackson). Armed with this distinction one can easily see that the big debate between empiricists (Carnap and others) and their relativistic outgrowth (Feyerabend, Kuhn) on the one hand and realists (Putnam, Boyd, etc.) on the other

\footnotetext{
${ }^{8}$ See also the related criticism of Zangwill (2001).

9 Best elaborated perhaps in Chalmers (1996), Haas-Spohn (1995), and Jackson (1998), but see also Kupffer (2003).

${ }^{10}$ Clear differences already show up in the works referred to in the previous footnote.
} 
simply falls victim to that ambiguity. The two parties are talking at cross-purposes about different kinds of intensions or meanings, and both of them may be accommodated in the two-dimensional framework. ${ }^{11}$

\section{On the Objectivity of Beliefs}

Let us move then to the other important notion of objectivity that relates rather to beliefs than to facts. What are we seeking here? The point is not about the having of beliefs. Whether or not I have a given belief is presumably just as objective as any other fact. It is rather the objectivity of belief contents we are interested in. This remark gives immediately rise to the observation that our inquiry of objectivity is about to cover the two-dimensional scheme just alluded to. We have talked about the objectivity of facts, or intensions or secondary or C-intensions, and we now attend to the objectivity of belief content, or diagonals or primary or A-intensions.

What are we after, though, with the objectivity of belief contents? Clearly, the issue is about the objective truth, or the objective falsity, of belief contents. If we identify, however, belief contents with states of affairs or somehow treat them on a par and thus reduce the truth of a belief content to the obtaining of a state of affairs or a fact ${ }^{12}$, then we are back at the issue of the previous section. Hence, we should look for a different approach. There is indeed one; we all have the idea that in principle everybody should be able to agree to objective truth and to reject objective falsity, and that there is no objectivity to the extent there is no such agreement. The idea at least sounds different from the one discussed in the previous section. So, let us pursue a little bit and then see whether it is really different.

Let me start by defining that an assertion or a statement $p$ (or rather its content, because this, and not the linguistic form, is what we are interested in) is shared by a group $G$ or intersubjectively accepted in $G$ if all members of $G$ who have a judgment on it accept or endorse $p$; and we may call $p$ intersubjective in $G$ if acceptance of $p$ or rejection of $p$ (or suspension of judgment concerning $p$ ) is shared in $G$, and subjective in $G$ otherwise. These relative notions are introduced only for

\footnotetext{
${ }^{11}$ Cf. also Haas-Spohn (1997, sect. 4).

12 The reader will notice that I am somewhat clumsily avoiding the notion of a proposition - precisely because it has played an unfortunate double role like the notion of intension, which is clearly split up in two in two-dimensional semantics.
} 
the sake of explicitness. Usually, some large group tacitly understood is the standard by which subjectivity and intersubjectivity are measured, say the linguistic community of all Americans or scientific communities sharing some expert language.

For instance, "I am tired" is clearly subjective, because I am accepting it as I am writing these words. "Philosophy is fun" is shared, I hope, by all readers of this paper (at least before reading it), but it is clearly a minority opinion in larger groups. However, "philosophy is easy" is, I take it, intersubjective since everybody thinking about it would deny it.

Now, the crucial question is, of course, what has intersubjective acceptance to do with objective truth? Not much, it seems. Each person is fallible in principle (though there may be a few things on which she is infallible); this is a lesson we have learned for a long time. Hence, subjective acceptance and truth may (almost) always fall apart. The same holds, then, for any actual group of persons. Why should a million people differ in principle from a single person? Some bit of counterfactuality does not change much here. If all the people in the relevant group would get all the information they can actually get, would be perfectly rational, would freely discuss their issues, and would then agree on a critical and considered judgment, they still might be wrong. The sources of error need not lie in factual imperfections of the group. All the evidence actually available to us might be, as it were, objectively misleading. Hence, any crude or mildly refined consensus theory of truth ${ }^{13}$ will not do. ${ }^{14}$

This is not to say that there is no relation at all between intersubjective acceptance and objective truth. A lot of counterfactuality does change the picture. The Peircean limit of inquiry always appeared to me to be an attractive idea. The consensus reached after all possible experience is acquired and all powers of reasoning are perfectly exerted must be true. Note that the consensus is no longer doing any real work here. Counterfactually, everybody has the same complete evidence including information about what the others think and the same ideal powers of reasoning. Then, we might suppose, consensus falls in.

The ideal is indeed vastly counterfactual. We cannot travel far enough in space-time in order to inquire what is going on at every space-time point; our

\footnotetext{
13 Such as the one of Habermas (1973) who does not refer to stronger counterfactual conditions than the ones just mentioned; however, he claims only to state a criterion of truth.

14 As Tara Smith has rightly observed in her contribution to this volume, from comments on which my contribution has emerged.
} 
memory and our computation are much too poor to process the counterfactual evidence; and we cannot undo the effects of our investigation and let the world go on as if unobserved. But under this vastly counterfactual assumption all possibility of error is excluded; nothing can turn up to prove us wrong. Or, as Putnam would have it, the ideal theory must be true. ${ }^{15}$

Is this really so? There are two opposite lines of attack, one saying that Putnam's claim is wrong and the other saying that it is too trivially true to be of any value. Let me briefly discuss the two criticisms.

The metaphysical realist insists that the ideal theory might still be wrong, an assertion Putnam fought with so many words. However, we know by now, indeed through Putnam's help, that the "might" might indicate metaphysical or epistemic possibility, and then the metaphysical and the internal realist do not seem to have any dispute. Under the metaphysical reading the metaphysical realist is clearly right. If we have acquired complete evidence about the actual world and build our ideal theory on that basis by exerting our ideal powers of reasoning, if we have thus reached the ideal limit of inquiry concerning the actual world, there is still a possible world in which we have acquired the same evidence and build the same ideal theory, but in which this theory is wrong. I do not find it particularly difficult to imagine such a possible world; one simple trick is that the evidence is supposed to be complete only with respect to the actual world, but not with respect to the imaginal world. Hence, it cannot be this metaphysical possibility which Putnam is fighting. It is rather an epistemic impossibility that the ideal theory is false. This theory cannot turn out to be false, there is nothing left which could show us that we erred. This appears obvious, but the metaphysical realist need not take exception to it.

What about the other criticism that it is too obvious? What is the criticism here? It is ${ }^{16}$ that the ideal limit of inquiry, the ideal theory, and the like are empty notions. What we would believe in this counterfactual limit does not inform us about objective truth; rather, we have to appeal to objective truth in order to arrive at a correct description of those counterfactual conditions excluding error. If we thus have to build in truth into the ideal, it is not a deep philosophical discovery that the ideal comes out true.

\footnotetext{
15 Putnam (1981, pp. 55f.) says: “... truth is an idealization of rational acceptability. ...the two key ideas of the idealization theory of truth are (1) that truth is independent of justification here and now, but not independent of all justification. ... (2) truth is expected to be stable or 'convergent'."

${ }^{16}$ Cf., e.g., Brandom (1994b).
} 
I do not agree with this criticism. I rather believe that internal realism, the claim that the ideal theory cannot turn out false, has substantial consequences concerning the relation between rationality and truth. Insofar I am a good Kantian. Indeed the consequences cut two ways.

One way is that the accessibility of truth constrains the rationality of belief states. For instance, the so-called Reichenbach axiom in inductive logic postulating that subjective probabilities must converge to observed relative frequencies is an axiom in this spirit and it puts a severe constraint on a priori subjective probabilities. ${ }^{17}$ Extensive and systematic investigation about such constraints are provided by formal leaving theory. ${ }^{18}$

The other way is that the rationality of belief states constrains truth. Whatever the state is which is reached in the ideal limit, it must still be governed by the laws of rationality, and to the extent we can establish such laws without recourse to truth we may thus draw conclusions concerning the structure of truth. For instance, the probability axioms, or the axioms of AGM belief revision theory ${ }^{19}$, or the axioms of ranking theory ${ }^{20}$, etc., provide such laws, which we can seek to strengthen. Thus we may arrive at principles a priori true in all possible limits of inquiry. ${ }^{21}$ Indeed, I guess most of the attempts to transcend correspondence, semantic, or deflationary views of truth can be, perhaps somewhat swiftly, subsumed here; I think, e.g., of pragmatic truth theories, the coherence theory of truth $^{22}$, evaluative theories of truth ${ }^{23}$, or even Brandom's expressivistic and inferentialistic strategy. ${ }^{24}$ All these approaches have at least the potential of arriving at substantial a priori truths.

This provokes a side remark: Philosophers still struggle with disentangling $a$ priori truth and analytic truth. This is difficult because both seem to be conceptual truths. Kripke made a distinction by defining analyticity as a priori necessity. This was revolutionary since it opened the non-empty category of a priori contingen-

\footnotetext{
${ }^{17}$ Cf., e.g., Carnap (1980, sect. 20).

${ }^{18}$ Cf. in particular Kelly (1996).

19 Cf., e.g., Rott (2001).

${ }^{20}$ Cf. Spohn (1988).

21 In Spohn (1991 and 1999) I tried to establish some weak coherence and causality principles in this way.

${ }^{22}$ As elaborated by Rescher (1973).

23 As Ellis (1990) calls them, elaborating and defending a specific version in ch. 7.

${ }^{24}$ Cf. Brandom (1994a). Though Brandom there defends a deflationary theory of truth (sect. 5.V), the further reaching goal I am attributing to him returns under the heading "objectivity".
} 
cies. But the conceptual was still the only source of the a priori. The previous paragraph points the way to a broader base of the a priori consisting of the structure of reason as a whole, and there is more to reason than concepts.

In any case, the rebuttal of the objection that the ideal limit of inquiry presupposes the notion of objective truth is important in our present dialectic situation. If we would have been forced to grant the objection, then we would have to admit as well that what we are heading for presently is not really a new notion of objectivity. Rather, we would have to start with objective truth, the limit of inquiry would approach just that and would not add an independent element, and then it is difficult to see in which ways the objectivity of truth differs from the objectivity of facts already discussed. But, if I am right, this is not our worry, and we may assume to have captured a different notion of objectivity, namely as intersubjectivity in that vastly counterfactual community reaching the ideal limit of inquiry.

How far does objectivity in this sense extent? Not nowhere, not everywhere; it depends. And it may not be easy to answer; after all, we are speculating about what would happen in that vastly counterfactual limit. Still, there seem to be many clear cases.

For instance, whether there was a dinosaur standing exactly at the place where I am sitting now exactly 25 billion days ago is an objective matter. In the ideal limit we all would agree on it even if we actually have no ways at all to find out about it. This seems to hold for all reports of singular facts about any place and time in the world. Moreover, we say that the theories of present-day science are better than those of former centuries, not simply different ones. This shows at least that we are confident in principle to be able to convince everybody including our colleagues from the former centuries of the theoretical progress and that we thus treat the theories as objective. I do not see why this should be unjustified.

What I would like to resist, in particular, is the thought that we are barred from objectivity and are at best struck with intersubjectivity within our linguistic community simply because we all are prisoners of our conceptual schemes. Conceptual schemes can be changed, indeed reasonably changed, they can be translated, and they can be merged, indeed translation may rather be merging, and so on. These processes are difficult to describe, and there is a lot of philosophical dispute about them. But, no doubt, they are effective. Hence, I don't see why we should be bound to end up with several incommensurable conceptual schemes. On the contrary, empirical concepts essentially refer to objects and properties that are 
objective in the first sense and thus not constituted by these concepts, and this at least opens the way for translating and unifying conceptual schemes.

There are also many cases of subjective assertions. Indexicality is one clear source of non-objectivity. "I am tired" is something I accept now, but not always, and many don't accept it. Sometimes, the relativity of an assertion to the circumstances of its utterance is written into the semantic rules of its expressions as in the case of indexicals. Sometimes, it is more implicit "Lucas is tall?" It depends on the context. "Philosophy is fun?" For me, but not for everybody. Hence, all such, in one or the other way relative assertions are not objective. However, they can be turned into objective ones by having their relativization made explicit. "Wolfgang is tired at January 6, 2002, 1 a.m.", "Lucas is tall for his age, but not within his class", "philosophy is fun for Wolfgang": all this is perfectly objective. If the source of subjectivity is relativity, then, it seems, objectivity can always be reached by appropriate explicit relativization. ${ }^{25}$

There is a further clear case of non-objectivity in the present sense, namely the case of self-verifying beliefs or, more generally, of beliefs causally affecting their own truth. If we believe the economic future is bright, it is bright, but not if we believe it is dull. The medicine helps if I believe it helps, it doesn't if I don't believe in it. If I expect my kids to be well-behaved they aren't, if I fear my kids to be naughty they aren't, either. These are strange ways of positive or negative feedback. And they hamper objectivity. The point is not relativity of content. We can eliminate the relativity and still have the feedback. The point is that what is accepted in the limit causally depends on what is accepted in the beginning, and hence there is no unique limit and thus no objectivity. It was generally sensed that there is something fishy about these self-confirming or self-affecting beliefs. It consists precisely in their deviant lack of objectivity; they don't behave like normal beliefs.

I have been careful at the beginning of this section to generally define the subjective and intersubjective acceptance and the objective acceptability of assertions. In my examples I have considered only assertions expressing beliefs (except perhaps "philosophy is fun"). Hence, I was so far only discussing the objectivity of beliefs. But the definitions clearly apply as well to other kinds of assertions

25 See also Mühlhölzer (1988) who elaborates and defends an explicitness conception of objectivity the clearest expression of which he ascribes to Hermann Weyl. 
which express other kinds of attitudes. Thus we can discuss the objectivity of these further kinds of assertions on the same model as those of beliefs.

\section{On the Objectivity of Values ${ }^{26}$}

The paradigm assertions for which objectivity issues have become historically eminently important are, of course, religious ones. Religious assertions are partly descriptive; they contain a picture of how the world is and works. But this picture does not exhaust their content. Rather, a bunch of different attitudes, in particular moral and evaluative ones, indeed a whole form of life meshes in them. I cannot see why their descriptive content as such should not be objective. ${ }^{27}$ But their content as a whole is certainly not objective, as a long and bloody history has taught us; at best intersubjective agreement within religious communities can be reached. The insight, though, that religious assertions are not objective, is, or is generally thought to be, the axe at the root of religion. This is why religious tolerance is so hard to reach.

The example shows the enormous difficulties arising from mixed discourse. If one sides with Smith (2000) on the objectivity of evaluative discourse, then it mixes well with objective descriptive discourse. ${ }^{28}$ If not, one faces the task of disentangling the mixed discourse into components of varying objectivity, often a difficult task, as we just saw, and one we shall not pursue now. Let us rather only try to get clearer on one particularly important component, the objectivity of evaluative or normative assertions. ${ }^{29}$

The central claim of Smith (2000, ch. 4) is that life is the source of all values. Perhaps the source is smaller; I doubt that flowers or earthworms are capable of values. But, certainly, inanimate objects cannot have values. Smith continues that at the same time life is itself a value or an end; indeed, it is "the ultimate value insofar all other genuine values depend on it and are the means to it" (p. 104). It is

\footnotetext{
26 This section shows most clearly the origin of the paper as a commentary on Tara Smith's contribution. She has most pronounced opinions on the objectivity of values that are also expressed in her paper and form that part of the paper to which I would like to oppose most.

27 Indeed, it is objectivity false, I assume; I cannot believe that any of the religious world pictures survives in the limit of inquiry.

${ }^{28}$ As she confirms on pp. 101ff.

29 Perhaps I am bit careless in this section in interchangeably talking of norms and values. But whatever the distinctions to be drawn here, they do not become relevant in our present context.
} 
an innate value of living beings to maintain life ${ }^{30}$, including flourishing and not mere vegetating. And all the values that we objectively have according to Smith (2000) derive from this fundamental value.

However, I don't think that the derivation can succeed. One reason for my doubt stems from a general analogy. Quine repeatedly claimed that truth is the ultimate value of all cognitive activity and that normative epistemology is just branch of engineering, the technology of truth-seeking. ${ }^{31}$ Thus, epistemology becomes naturalized. In view of the utterly rich normative discussion in epistemology this claim always appeared to me to be entirely unredeemed. Perhaps, epistemology can be unified under this goal, but nobody can claim to have shown this. ${ }^{32}$ And what is true of epistemic norms, is all the more true of norms and values in general.

This was only an analogy so far, not an argument. So let us look directly at values. Some values seem to belong to our biological endowment and thus to be objective. For instance, "I am alive" or "I am without pain" are assertions the content of which everybody values. No doubt, but this is due to the indexicality of these assertions. Making their relativization explicit has here a subjectivizing effect, opposite to the case of beliefs. "Wolfgang is alive" or "Wolfgang is without pain" is valued by me, but not necessarily by my neighbors. Hence, the values we are biologically endowed with are, on the contrary, highly subjective. ${ }^{33}$

This fact is at the root of all moral conflicts and of all difficulties of attaining evaluational objectivity. Usually, staying alive is a cooperative enterprise to the benefit of all, but much too often we have to weigh life against life (and even life against money). Often, flourishing is a mutual activity, and often flourishing is exclusive and excessive at the expense of others. Smith (2000) is, of course, aware of such problems and discusses them in chapter 6. I don't think they dissolve so easily.

Fehige (2003) tries to stop the argumentative gap right at the beginning. He argues that I should value not only my absence of pain or, more generally, my posi-

\footnotetext{
${ }^{30}$ Until its natural end - where different ideas about the natural end of life seem to be encoded in different species; see, e.g., salmons.

31 Cf., e.g., Hahn, Schilpp (1986, pp. 664f.). This is just the above discussed, uninteresting sense of the ideal limit of inquiry reaching the truth.

${ }^{32}$ Indeed, I interpret Quine (1995, pp. 49f.) as stepping back a bit from his earlier bold claims.

33 One needs to be careful here. "Wolfgang values absence of pain" describes an objective fact (in the first sense) and expresses an objectively true belief (in the second sense), but "Wolfgang is without pain" is subjectively valued by me, not necessarily intersubjectively by everyone.
} 
tive hedonic states, but also those of all others. Empathy is an a priori moral principle, he argues. This is at least plausible. If so, however, it follows that my positive satisfactive states should be valued, and the negative ones disvalued, by everyone, not only by me. This does not yet quite mean that these values are objective ones. Fehige rather tries to establish even more, namely that my hedonic states should be valued by others to the same degree as I do, and vice versa. Indeed, only then the objectivity of the evaluation of the hedonic states, which is a quantitative, not a qualitative affair, would be guaranteed.

The argument is an intricate one, but I doubt whether it succeeds. To this extent it is doubtful whether we have reached an objective base of our evaluations. But even if we would have reached it, we could build far less on it than, e.g., Smith (2000) thinks. In arguing this, I have a little terminological difficulty. The talk of hedonic or satisfactive states is mine, not Smith's. She is not a hedonist. Her concern is rather living and flourishing which she takes in an Aristotelian sense. And given the objective values of living and flourishing, she argues that it is an objective empirical question when and how we stay alive and when and how we flourish. Hence, the conditions under which we stay alive and flourish are objectively valuable as well. However, flourishing has certainly a lot to do with hedonic states. And the hedonist might take a similar stance, namely that it is an objective empirical issue when and how our hedonic states are pleasant and not painful and that further values may thus be objectively inferred from the value of our hedonic states. It is the latter claim I want to oppose, but my point applies, it seems, just as well against Smith's stance.

My point is simply that the self-confirming structure that we found to be rare and deviant in the case of beliefs is quite common in the case of values. Or more generally, it is not at all rare or deviant, but perfectly normal that values causally affect their own acceptability and maintainability. If I desire to be a philosopher, if being a philosopher is a subjective value for me, being a philosopher makes me happy; but it would be agonizing to be a philosopher without valuing it. If a pregnant woman wants to have a baby, she will derive immense satisfaction from it. If she rejects it, she is likely to be torn in conflict and ambiguity. These are normal self-confirming cases. But the structure may be more pathological. A desire may be so insatiable that each fulfillment of the desire is rather painful than pleasant. A 
man may long for inaccessible women; as soon as a woman responds to his courting, he starts rejecting her. The list of examples is endless. ${ }^{34}$

The general logical point of these examples is this: Very often, or even usually, so-and-so much valued satisfactive states are causally affected not merely by the realization of a valued state of affairs, but also by that state of affairs being valued so-and-so much. Hence, the value of that state of affairs cannot be simply derived from its propensity to produce happiness. Rather, its value must somehow be given beforehand, and then its evaluation can be confirmed, or disconfirmed, by its propensity to produce happiness as one valued to this degree. So, what we humans have to seek is rather a kind of equilibrium between our evaluations of the various states of affairs and their causal affect on hedonic states, if thus valued. There are as many equilibria as there are happy persons or flourishing and fulfilled lifes. Each one is subjective, and so are the values maintaining it. ${ }^{35}$ This is the deeper wisdom behind the German saying “jeder ist seines Glückes Schmied".

The point just sketched reappears, I believe, on the intersubjective level. The constitution of societies - understood widely as the collection of their legal codes, moral rules, social values, customs, etc. - may very greatly, without there being an external arbiter proving them wrong or immoral or inacceptable. In the positive case, various religious communities may be happy and stable without suppressing its member. The balance between individual rights and social duties, between liberalism and communitarianism may take many forms. All societies struggle with intergenerational justice, and they find many different solutions. And if our societies are discussing such problems and changing their terms, they need not be moving towards an objective ideal, but rather only towards an improved internal equilibrium.

This is not a pleading against patronizing or for saying de gustibus non est disputandum, which is only very limitedly true. It is only a reminder that one should be very clear about one's base for criticizing and patronizing others. Often, this base is not objective, but subjective. Either in the sense that one declares one's

\footnotetext{
34 Elster $(1979,1983)$ is famous for collecting and analyzing many of such more or less paradoxical situations. One must pay attention, though. There is great variation in the logical structure and analysis of these situations.

35 This description may sound confusing, or confused. In Kusser, Spohn (1992) we have analyzed the problem (which we traced back at least to Joseph Butler) in detail and with decision-theoretic precision, and we have tried to disentangle the confusions that invariably adhere to brief sketches of the problem like this one. We are convinced that the problem has important consequences for decision theory and for the view of practical rationality in general.
} 
own subjective point of view; this tends to be futile. Or in the sense that one criticizes the other's subjective point of view for its internal inconsistencies, where "inconsistency" takes on a broader range in the light of the preceding paragraph. For instance, the man's longing for inaccessible women is broadly inconsistent in the relevant sense; one should help, i.e., patronize him, and not let him remain in his unhappy condition. ${ }^{36}$

All this is even not a pleading against the objectivity of values, against an objective basis for such criticism. I hope and believe that there is such objectivity. Indeed, most do; at least, most moral issues are discussed as if there would be an objective answer. One must grant, of course, that this objectivity is in no way settled. This is what moral philosophy is all about. There are rival conceptions of moral norms and values, there are rival justifications for them, and the claims of objectivity depend on the quality of these justifications. If, for instance, the long sought derivation of substantial moral principles from principles of rationality alone finally succeeds, the two kinds of principles are distinguished by the same degree of objectivity. Whether the justifications are compelling enough to produce general agreement, whether the limit of moral inquiry is unique and the unity of practical reason perfect, is nice to speculate, but hard to argue.

But even if the answer is positive, the extent of the objectivity of norms and values is open. Basic moral principles like the Golden Rule, the Categorical Imperative, or the Principle of Universalizability are good candidates; basic human rights are so as well. But where the boundary is to be drawn above which objectivity reigns and below which the various reasons for non-objectivity specified above set in, that is hard to tell.

In any case, though, the objectivity in normative and evaluative matters differs from that in descriptive matters. Normative or evaluative discourse is autonomous, not reducible to descriptive discourse about empirical matters. And unlike the latter, the objectivity to which it possibly raises is not helped by the ontological independence and the objectivity of facts, properties, and objects.

\footnotetext{
${ }^{36}$ For a more systematic development of this thought see Kusser (1989); for a different approach see, e.g., Brandt (1979).
} 


\section{References}

Bennett, J. (1971), Locke, Berkeley, Hume, Oxford: University Press.

Brandom, R. (1994a), Making It Explicit, Cambridge, Mass.: Harvard University Press.

Brandom, R. (1994b), “Unsuccessful Semantics”, Analysis 54, 175-178.

Brandt, R. (1979), A Theory of the Good and the Right, Oxford: Clarendon Press.

Carnap, R. (1980), “A Basic System of Inductive Logic, Part 2”, in: R. C. Jeffrey (ed.), Studies in Inductive Logic and Probability, vol. II, Berkeley: University of California Press, pp. 7-155.

Chalmers, D. J. (1996), The Conscious Mind, Oxford: Oxford University Press.

Devitt, M. (1984), Realism and Truth, Oxford: Blackwell.

Ellis, B. (1990), Truth and Objectivity, Oxford: Blackwell.

Elster, J. (1979), Ulysses and the Sirens. Studies in Rationality and Irrationality, Cambridge: Cambridge University Press

Elster, J. (1983), Sour Grapes. Studies in the Subversion of Rationality, Cambridge: Cambridge University Press.

Fehige, C. (2003), Soll ich?, Stuttgart: Reclam.

Haas-Spohn, U. (1995), Versteckte Indexikalität und subjektive Bedeutung, Berlin: AkademieVerlag.

Haas-Spohn, U. (1997), “The Context Dependency of Natural Kind Terms”, in: W. Künne, A. Newen, M. Anduschus (eds.), Direct Reference, Indexicality and Propositional Attitudes, Stanford: CSLI Publications: Stanford, pp. 333-349.

Habermas, J. (1973), "Wahrheitstheorien”, in: H. Fahrenbach (ed.), Wirklichkeit und Reflexion. Walter Schulz zum 60. Geburtstag, Pfullingen: Neske, pp. 211-265.

Hahn, L. E., P. A. Schilpp (eds.) (1986), The Philosophy of W. V. Quine, La Salle, Ill.: Open Court.

Hume, D. (1739/40), A Treatise of Human Nature.

Jackson, F. (1998), From Metaphysics to Ethics, Oxford: Clarendon Press.

Jackson, F., R. Pargetter (1987), “An Objectivist's Guide to Subjectivism about Color”, Revue Internationale de Philosophie 41, 127-41.

Kaplan, D. (1977), "Demonstratives. An Essay on the Semantics, Logic, Metaphysics, and Epistemology of Demonstratives and Other Indexicals", in: J. Almog, J. Perry, and H. Wettstein (eds.), Themes from Kaplan. Oxford: Oxford University Press, 1989, pp. 481-563.

Kelly, K. T. (1996), The Logic of Reliable Inquiry, Oxford: Oxford University Press.

Kupffer, M. (2003), "Kaplan's Apriori”, Forschungsberichte der DFG-Forschergruppe "Logik in der Philosophie".

Kusser, A. (1989), Dimensionen der Kritik von Wünschen, Frankfurt a.M.: Athenäum.

Kusser, A., W. Spohn (1992), “The Utility of Pleasure is a Pain for Decision Theory”, Journal of Philosophy 89, 10-29.

Mühlhölzer, F. (1988), “On Objectivity”, Erkenntnis 28, 185-230.

Putnam, H. (1981), Reason, Truth and History, Cambridge: Cambridge University Press.

Quine, W. V. (1995), From Stimulus to Science, Cambridge, Mass.: Harvard University Press.

Rescher, N. (1973), The Coherence Theory of Truth, Oxford: Oxford University Press.

Rott, H. (2001), Change, Choice, and Inference, Oxford: Oxford University Press.

Smith, T. (2000), Viable Values, Lanham: Rowman \& Littlefield.

Spohn, W. (1988), "Ordinal Conditional Functions. A Dynamic Theory of Epistemic States", in: W. L. Harper, B. Skyrms (eds.), Causation in Decision, Belief Change, and Statistics, vol. II, Dordrecht: Kluwer, pp. 105-134. 
Spohn, W. (1991), “A Reason for Explanation: Explanations Provide Stable Reasons”, in: W. Spohn, B. C. van Fraassen, B. Skyrms (eds.), Existence and Explanation, Dordrecht: Kluwer, pp.165-196.

Spohn, W. (1997), "The Character of Color Predicates: A Materialist View", in: W. Künne, A. Newen, M. Anduschus (eds.), Direct Reference, Indexicality and Propositional Attitudes, Stanford: CSLI Publications: Stanford, pp. 351-379.

Spohn, W. (1999), “Two Coherence Principles”, Erkenntnis 50, 155-175.

Stalnaker, R. C. (1978), “Assertion”, in: P. Cole (ed.), Syntax and Semantics, Vol. 9: Pragmatics. New York: Academic Press, pp. 315-32.

Zangwill, N. (2001), “Against Moral Response-Dependence”, Erkenntnis 55, 271-276. 